\title{
Synthesis of calcium hydroxyapatite from calcium carbonate and different orthophosphate sources: A comparative study
}

\author{
Doan Pham Minh ${ }^{\mathrm{a}, *}$, Nathalie Lyczko ${ }^{\mathrm{a}}$, Haroun Sebei ${ }^{\mathrm{a}}$, Ange Nzihou ${ }^{\mathrm{a}}$, Patrick Sharrock ${ }^{\mathrm{b}}$ \\ a Université de Toulouse, Mines Albi, CNRS, Centre RAPSODEE, Campus Jarlard, F-81013 Albi cedex 09, France \\ ${ }^{\mathrm{b}}$ Université de Toulouse, SIMAD, IUT Paul Sabatier, Avenue Georges Pompidou, 81104 Castres, France
}

\begin{abstract}
A B S T R A C T
The synthesis of calcium hydroxyapatite (Ca-HA) starting from calcium carbonate and different orthophosphate sources, including orthophosphoric acid, potassium, sodium and ammonium dihydrogen orthophosphates, was investigated under ambient conditions. The reaction started with calcium carbonate dissolution in an acid medium, followed by rapid precipitation of calcium cations with orthophosphate species to form calcium phosphate based particles which were in the size range of $0.4-1 \mu \mathrm{m}$. These particles then agglomerated into much larger ones, up to $350 \mu \mathrm{m}$ in diameter (aggregates). These aggregates possessed an unstable porous structure which was responsible for the porosity of the final products. The highest specific surface area and pore volume were obtained with potassium dihydrogen orthophosphate. On the other hand, orthophosphoric acid led to the highest dissolution of calcium carbonate and the complete precipitation of orthophosphate species. Under ambient conditions, calcium phosphate based solid products of low crystallinity were formed. Different intermediates were identified and a reaction pathway proposed.
\end{abstract}

Keywords:

Calcium hydroxyapatite

Calcium carbonate

Orthophosphates

Ambient temperature synthesis

\section{Introduction}

Calcium hydroxyapatite (Ca-HA) continues to attract much attention owning to its many potential applications in fields such as medicine, wastewater treatment, and catalysis. For example, synthetic Ca-HA particles are used for coating metallic implants or bone grafts $[1,2]$. In heterogeneous catalysis, Ca-HA was found to be active in different reactions: oxidative dehydrogenation of light alkanes, water gas shift reaction, total oxidation of $\mathrm{CO}$, photodecomposition of organic pollutants, etc. [3-6]. Ca-HA also possesses very good retention capacities for heavy metals or organic pollutants in aqueous effluents [7-11] which confers a potential role for this calcium phosphate in environmental processes.

A great deal of effort has been devoted to the synthesis of CaHA and other apatitic products [12-16]. The genesis of carbonate apatites was first described by Ames [17], then by Krajewski [18] using calcium carbonate as insoluble calcium source. Carbonate apatites were also made using soluble salts as starting materials [19]. For Ca-HA, the standard synthesis calls for the use of soluble calcium salts $[20,21]$. The practically complete precipitation of calcium phosphate results from mixing the homogeneous solution of reactants. However, the use of soluble calcium salts requires the viscous Ca-HA precipitate to undergo a further purification step, so

\footnotetext{
* Corresponding author. Tel.: +33 563493258; fax: +33 563493043

E-mail address: doan.phamminh@mines-albi.fr (D. Pham Minh).
}

as to eliminate the associated anions. An alternate route for Ca-HA synthesis is the acid-base neutralization method using orthophosphoric acid and lime solutions as starting materials which contain not counter ions [22-24]. Calcium carbonate is also a good candidate for calcium source, thanks to its low cost, wide availability and the absence of interfering anions. Nevertheless, when it was used previously as a starting material, it was usually transformed into calcium oxide by a thermal treatment or into water soluble calcium salt by dissolution in an acid solution, prior to the Ca-HA synthesis $[25,26]$.

In the present work, a comparative study of the synthesis of CaHA from calcium carbonate and different orthophosphate sources was investigated. The main purpose of this study was to compare the dissolution of calcium carbonate, the precipitation of orthophosphate and the formed solids when different orthophosphate sources were used. Different characterization techniques were used for the analysis of the resulting solid products. The dissolution of calcium carbonate was highest with orthophosphoric acid but could not yield a complete, quantitative and stoichiometric Ca-HA precipitate after a long reaction time $(48 \mathrm{~h})$ at ambient temperature. Nevertheless, this pathway presents interesting industrial outlets.

\section{Materials and methods}

A fine powder of calcium carbonate $\left(\mathrm{CaCO}_{3}, 98 \%\right.$, Fisher Scientific) was used as calcium source. Ammonium dihydrogen 
orthophosphate $\left(\mathrm{NH}_{4} \mathrm{H}_{2} \mathrm{PO}_{4}, 99 \%\right.$, Fisher Scientific), potassium dihydrogen orthophosphate $\left(\mathrm{KH}_{2} \mathrm{PO}_{4}, 99 \%\right.$, Fisher Scientific), sodium dihydrogen orthophosphate $\left(\mathrm{NaH}_{2} \mathrm{PO}_{4}, \approx 100 \%\right.$, Fisher Scientific) and orthophosphoric acid $\left(\mathrm{H}_{3} \mathrm{PO}_{4}, 85 \mathrm{wt}\right.$.\% in water, Merck) were used as orthophosphate sources without further modification.

Ca-HA synthesis was carried out in a 1.2 liter (L) U-form glass reactor (i.d.: $10 \mathrm{~cm}$, length: $15 \mathrm{~cm}$ ), equipped with a vertical stirrer. In each synthesis, $0.6 \mathrm{~mol}$ of orthophosphate salts or orthophosphoric acid and $500 \mathrm{~mL}$ of water were fed into the reactor and homogenized under stirring. Then $1.0 \mathrm{~mol}$ of calcium carbonate were added to the orthophosphate solution at a rate of $2.5 \mathrm{~g} \mathrm{~min}^{-1}$, to avoid the overflowing of the liquid due to strong acid attack on calcium carbonate particles at low $\mathrm{pH}$. These reactant quantities corresponded to the $\mathrm{Ca} / \mathrm{P}$ molar ratio of 1.67 , which is the theoreti$\mathrm{cal} \mathrm{Ca/P} \mathrm{molar} \mathrm{ratio} \mathrm{of} \mathrm{Ca-HA.} \mathrm{The} \mathrm{reaction} \mathrm{was} \mathrm{kept} \mathrm{under} \mathrm{stirring}$ (400 rpm) for $48 \mathrm{~h}$ under ambient conditions $\left(25^{\circ} \mathrm{C}\right.$, atmospheric pressure). The $\mathrm{pH}$ of the reaction was monitored continuously throughout the reaction. During the reaction, samples were withdrawn from the reactor and filtered on a $0.45 \mu \mathrm{m}$ filter paper to separate liquid and solid phases. The solid was washed with permuted water and dried overnight in an oven at $105^{\circ} \mathrm{C}$ under air atmosphere.

Thermogravimetric analysis (TG) was carried out with a TA Instruments SDTQ600 analyzer. Heat-flow and weight changes associated with transitions and reactions in the products over the temperature range ambient to $1000^{\circ} \mathrm{C}$ (heating rate of $5^{\circ} \mathrm{C} \mathrm{min}-1$ ) under air atmosphere $\left(100 \mathrm{~mL} \mathrm{~min}^{-1}\right)$ were measured simultaneously. X-ray diffraction (XRD) data were collected using a Phillips Panalytical X'pert Pro MPD diffractometer with a $\mathrm{Cu} \mathrm{K} \alpha(1.543 \AA)$ radiation source and a nickel filter to suppress the $\mathrm{Cu} K \beta$ ray. Scanning electron microscopy coupled with energy dispersive spectroscopy (SEM-EDX) measurement was performed on a Philips XL30 ESEM apparatus (FEI Company). The particle size distribution of solid powders was measured by laser scattering in a Mastersizer 2000 (Malvern Instruments Ltd., Malvern, UK) in the range from 0.020 to $2000 \mu \mathrm{m}$. The specific surface area of the solids was measured by nitrogen adsorption following standard vacuum drying at $105^{\circ} \mathrm{C}$, using the BET method (MICROMETRICS Gemini Vacprep 061). The adsorption-desorption isotherm was determined with a MICROMETRICS ASAP 2010 using nitrogen as gas adsorbate with the data collection from relative pressure $\left(P / P^{\circ}\right)$ of $0.03-0.99$. Elemental analysis of the liquid phase was carried out using inductive coupled plasma atomic emission spectroscopy (ICP-AES) with a HORIBA Jobin Yvon Ultima 2 apparatus. The species distribution of orthophosphoric acid was computed using the solEq software (Academic Software, Yorks, UK) and the IUPAC stability constants database of 2004.

\section{Results and discussion}

\section{1. $p$ H evolution}

All four initial orthophosphate solutions had acid $\mathrm{pH}$ values. When calcium carbonate was added, it reacted immediately with the acid solutions, liberating carbonic gas. Taking into account the amount and addition rate of calcium carbonate into the acid solutions, the time taken for the complete addition of $\mathrm{CaCO}_{3}$ was $40 \mathrm{~min}$. Fig. 1 shows the evolution of recorded $\mathrm{pH}$ values during this period where most notable changes in $\mathrm{pH}$ evolution were observed.

All three orthophosphate salts showed similar $\mathrm{pH}$ profiles. They had the initial $\mathrm{pH}$ of ca. 3.9 which increased rapidly in the first minutes, accompanied by strong release of carbonic gas. This release was due to the acid attack on the calcium carbonate powder (Eq. (1)) where calcium cations were formed and protons were consumed. In

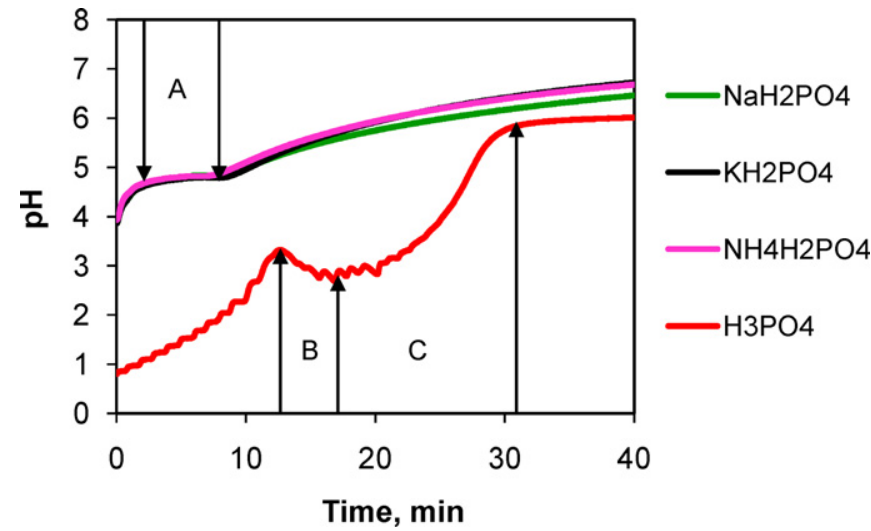

Fig. 1. $\mathrm{pH}$ evolution during the first fourteen $\mathrm{min}$ of the reaction using orthophosphoric acid (red); sodium dihydrogen orthophosphate (green); potassium dihydrogen orthophosphate (black) and ammonium dihydrogen orthophosphate (pink). (For interpretation of the references to color in this figure legend, the reader is referred to the web version of this article.)

the presence of different orthophosphate species, calcium cations were then rapidly precipitated (Eq. (2)).

$2 \mathrm{H}^{+}+\mathrm{CaCO}_{3} \rightarrow \mathrm{Ca}^{2+}+\mathrm{H}_{2} \mathrm{O}+\mathrm{CO}_{2}$

$\mathrm{Ca}^{2+}+$ orthophosphates $\rightarrow$ calcium orthophosphates

Fig. 2 recalls the distribution of orthophosphate species as a function of $\mathrm{pH}$ in the range $0-14$ in aqueous solution.

At the $\mathrm{pH}$ of 3.9 corresponding to the initial $\mathrm{pH}$ of aqueous solutions of orthophosphate salts, the species distribution was 2.46\%, 97.46\%, $0.05 \%$ and $0 \%$ for $\mathrm{H}_{3} \mathrm{PO}_{4}, \mathrm{H}_{2} \mathrm{PO}_{4}{ }^{-}, \mathrm{HPO}_{4}{ }^{2-}$, and $\mathrm{PO}_{4}{ }^{3-}$, respectively. With the presence of $\mathrm{H}_{2} \mathrm{PO}_{4}{ }^{-}$as the major orthophosphate anion in the solution, mono-calcium phosphate monohydrate (MCPM, $\left.\mathrm{Ca}\left(\mathrm{H}_{2} \mathrm{PO}_{4}\right)_{2} \cdot \mathrm{H}_{2} \mathrm{O}\right)$ was expected to precipitate at this early stage [27]. Eqs. (1) and (2) can be combined as follows:

$2 \mathrm{H}^{+}+2 \mathrm{H}_{2} \mathrm{PO}_{4}^{-}+\mathrm{CaCO}_{3} \rightarrow \mathrm{Ca}\left(\mathrm{H}_{2} \mathrm{PO}_{4}\right)_{2} \cdot \mathrm{H}_{2} \mathrm{O}+\mathrm{CO}_{2}$

After the initial increase, the $\mathrm{pH}$ stabilized during the continued addition of calcium carbonate powder into the reactor (zone A, Fig. 1). This $\mathrm{pH}$ plateau could be explained by the formation of a second intermediate - dicalcium phosphate dihydrate (DCPD, $\mathrm{CaHPO}_{4} \cdot 2 \mathrm{H}_{2} \mathrm{O}$ ) or brushite (Eq. (4)). The formation of DCPD accompanied the release of protons $\mathrm{H}^{+}$. So the equilibrium between the formation of protons $\mathrm{H}^{+}$in Eq. (4) and the consumption of protons $\mathrm{H}^{+}$in Eq. (1) led to the $\mathrm{pH}$ plateau in zone A (Fig. 1). After this $\mathrm{pH}$ plateau, the $\mathrm{pH}$ increased gradually to about 6.7 after 40 min

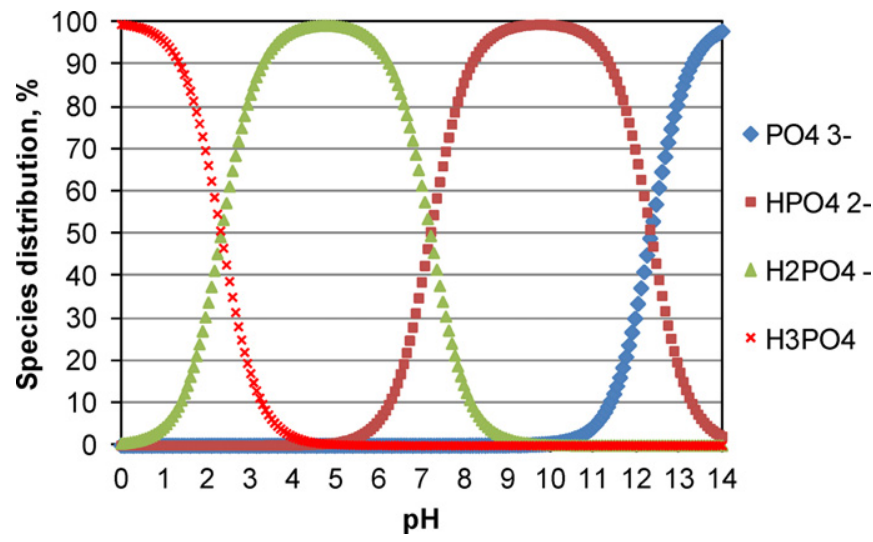

Fig. 2. Distribution of orthophosphate species in aqueous solution as a function of $\mathrm{pH}$. 
Table 1

Elementary analysis of soluble phosphorus and calcium in the liquid phase after $48 \mathrm{~h}$ of synthesis; $X_{\mathrm{P}}$ : conversion of initial soluble phosphorus into solid calcium phosphate products.

\begin{tabular}{lcll}
\hline Initial phosphate & $P(\mathrm{mmol})$ & $X_{\mathrm{P}}(\%)$ & $\mathrm{Ca}(\mathrm{mmol})$ \\
\hline $\mathrm{H}_{3} \mathrm{PO}_{4}$ & 0.5 & 99.9 & 0.8 \\
$\mathrm{KH}_{2} \mathrm{PO}_{4}$ & 240 & 60.0 & 0.2 \\
$\mathrm{NaH}_{2} \mathrm{PO}_{4}$ & 220 & 63.3 & 0.3 \\
$\mathrm{NH}_{4} \mathrm{H}_{2} \mathrm{PO}_{4}$ & 229 & 61.8 & 0.6 \\
\hline
\end{tabular}

of reaction, which can be explained by the continuous acid consumption (Eq. (1)) and the evolution of MCPM and DCPD into other calcium phosphates.

$\mathrm{Ca}\left(\mathrm{H}_{2} \mathrm{PO}_{4}\right)_{2} \cdot \mathrm{H}_{2} \mathrm{O}+\mathrm{Ca}^{2+}+3 \mathrm{H}_{2} \mathrm{O} \rightarrow 2\left[\mathrm{CaHPO}_{4} \cdot 2 \mathrm{H}_{2} \mathrm{O}\right]+2 \mathrm{H}^{+}$

In the case of orthophosphoric acid, the initial $\mathrm{pH}$ was 0.8 . At this $\mathrm{pH}$, the species distribution was the following: $96.81 \%, 3.19 \%$, $0 \%$ and $0 \%$ for $\mathrm{H}_{3} \mathrm{PO}_{4}, \mathrm{H}_{2} \mathrm{PO}_{4}{ }^{-}, \mathrm{HPO}_{4}{ }^{2-}$, and $\mathrm{PO}_{4}{ }^{3-}$, respectively. The first increase in $\mathrm{pH}$ (before zone B, Fig. 1) was due to the consumption of protons $\mathrm{H}^{+}$(Eq. (1)) and the time-length of this increase was longer than that of orthophosphate salts. So the quantity of MCPM formed was logically more than that from orthophosphate salts. After this first increase, the $\mathrm{pH}$ decreased (zone B, Fig. 1) despite the addition of calcium carbonate powder into the reactor. This drop in $\mathrm{pH}$ could also be attributed to the release of protons $\mathrm{H}^{+}$ coming from the transformation of MCPM into DCPD (Eq. (4)) at a rate higher than that of the consumption of protons $\mathrm{H}^{+}$in Eq. (1). This phenomenon was also observed by Kim et al. in the synthesis of Ca-HA from $\mathrm{Ca}(\mathrm{OH})_{2}$ and orthophosphoric acid [28]. After the decrease in zone $\mathrm{B}$, the $\mathrm{pH}$ increased in zone $\mathrm{C}$ (Fig. 1) explained by the fact that in zone $\mathrm{C}$, the transformation of MCPM into DCPD (Eq. (4)) reached equilibrium while protons $\mathrm{H}^{+}$were still continuously consumed by Eq. (1). After zone C, the pH increased slightly indicating the slow evolution of MCPM and DCPD into other calcium orthophosphates. From $40 \mathrm{~min}$ to $48 \mathrm{~h}$ of reaction, the $\mathrm{pH}$ increased continuously and stabilized to about 8 for orthophosphate salts and 6.8 for orthophosphoric acid.

\subsection{Elemental analysis of the liquid phase}

Much work has been done on the synthesis of Ca-HA but the liquid phase has usually not been analyzed although it is indispensable to evaluate the performance of the synthesis process.

Table 1 reports the contents of soluble phosphorus and calcium in the liquid phase, obtained by ICP-AES analysis. In all cases, the content of soluble calcium was very low after $48 \mathrm{~h}$ of reaction. So, most calcium existed in the solid state under either calcium phosphate products or non-dissolved calcium carbonate. The soluble phosphorus initially introduced in the reactor was $600 \mathrm{mmol}$. After $48 \mathrm{~h}$ of reaction, orthophosphoric acid led to a complete precipitation of soluble phosphate species into solid calcium phosphates. On the other hand, all three orthophosphate salts resulted in lower yields of precipitation of orthophosphate species which never exceed $64 \%$. Probably the presence of $\mathrm{K}^{+}, \mathrm{Na}^{+}$and $\mathrm{NH}_{4}{ }^{+}$ cations in the reaction mixtures caused this incomplete precipitation of orthophosphate species. In fact, after $48 \mathrm{~h}$ of reaction using orthophosphate salts, the concentration of $\mathrm{OH}^{-}$was of ca. $10^{-6} \mathrm{~mol} \mathrm{~L}^{-1}$ because the final $\mathrm{pH}$ was of $\mathrm{ca}$. 8 . This concentration of $\mathrm{OH}^{-}$anions was very small in comparison with that of $\mathrm{K}^{+}, \mathrm{Na}^{+}$and $\mathrm{NH}_{4}{ }^{+}$cations. During the reaction, the initial solid carbonate was essentially transformed into carbonic gas by acid attack (Eq. (1)). Thus, the contents of $\mathrm{HCO}_{3}{ }^{-}$and $\mathrm{CO}_{3}{ }^{2-}$ in the final liquid phase must also be low. Logically in the synthesis using orthophosphate salts, some of initial orthophosphate species had to be present in the liquid phase as counter ions of $\mathrm{K}^{+}, \mathrm{Na}^{+}$or $\mathrm{NH}_{4}^{+}$cations. Under the present synthetic conditions, $36-40 \%$ of initial orthophosphate
Table 2

Evolution of calcium carbonate content remaining in the solid product calculated from the results of TG analysis.

\begin{tabular}{lllll}
\hline Reaction time (h) & \multicolumn{4}{l}{$\mathrm{CaCO}_{3}$ content (\%) } \\
\cline { 2 - 5 } & $\mathrm{H}_{3} \mathrm{PO}_{4}$ & $\mathrm{NaH}_{2} \mathrm{PO}_{4}$ & $\mathrm{KH}_{2} \mathrm{PO}_{4}$ & $\mathrm{NH}_{4} \mathrm{H}_{2} \mathrm{PO}_{4}$ \\
\hline 1 & 27 & 54 & 50 & 52 \\
3 & 25 & 50 & 45 & 45 \\
7 & 25 & 48 & 43 & 43 \\
24 & 23 & 43 & 43 & 43 \\
31 & 20 & 41 & 41 & 41 \\
48 & 18 & 34 & 34 & 35 \\
\hline
\end{tabular}

salts could not be converted into solid calcium phosphate products. This demonstrated the interest of the use of orthophosphoric acid instead of orthophosphate salts.

\subsection{TG analysis}

To better understand the evolution of intermediates during the reaction, solid samples withdrawn from the reaction mixture were washed, dried and then analyzed by different techniques. Fig. 3 shows the derivative thermogravimetry (DTG) curves in the temperature range from $25^{\circ} \mathrm{C}$ to $1000^{\circ} \mathrm{C}$.

In this section, $\mathrm{DTG}_{\max }$ indicates the temperature corresponding to the maximum of the DTG signal. In Fig. 3(A), all samples had a small weight loss at the temperature lower than $100^{\circ} \mathrm{C}$, which was attributed to the elimination of physically absorbed surface moisture. The second weight loss occurred at the DTG $\mathrm{max}_{\max }$ of $110^{\circ} \mathrm{C}$, which was due to the dehydration of MCPM (Eq. (5)). The next weight loss, much more abrupt, took place at the DTG $\max$ of $186^{\circ} \mathrm{C}$ and could be attributed to the dehydration of DCPD to form dicalcium phosphate anhydrous - DCPA (Eq. (6)). This last product was later condensed at the DTG $\max$ of $430^{\circ} \mathrm{C}$ into calcium pyrophosphate (Eq. (7)) [27]. The last and largest weight loss at the DTG max $_{\text {of }}$ $705^{\circ} \mathrm{C}$ was due to the decomposition of the remaining calcium carbonate, according to reaction (Eq. (8)). The intensity of peaks related to calcium carbonate decomposition decreased progressively with the reaction time, indicating the continuous advancement of the reaction consuming the solid carbonate (Table 2 ).

$$
\begin{aligned}
& \mathrm{Ca}\left(\mathrm{H}_{2} \mathrm{PO}_{4}\right)_{2} \cdot \mathrm{H}_{2} \mathrm{O} \rightarrow \mathrm{Ca}\left(\mathrm{H}_{2} \mathrm{PO}_{4}\right)_{2}+\mathrm{H}_{2} \mathrm{O} \\
& \mathrm{CaHPO}_{4} \cdot 2 \mathrm{H}_{2} \mathrm{O} \rightarrow \mathrm{CaHPO}_{4}+2 \mathrm{H}_{2} \mathrm{O} \\
& 2 \mathrm{CaHPO}_{4} \rightarrow \mathrm{Ca}_{2} \mathrm{P}_{2} \mathrm{O}_{7}+\mathrm{H}_{2} \mathrm{O} \\
& \mathrm{CaCO}_{3} \rightarrow \mathrm{CaO}+\mathrm{CO}_{2}
\end{aligned}
$$

Fig. 3(B) illustrates the DTG curves when sodium dihydrogen orthophosphate was used. MCPM was present in all samples in very small amounts while DCPD and DCPA decreased with the reaction time and had almost disappeared after $48 \mathrm{~h}$ of reaction. On the other hand, calcium carbonate was found at higher levels in comparison to those in Fig. 3(A), as was also observed for Fig. 3(C) and (D) corresponding to the use of potassium and ammonium dihydrogen orthophosphates. As illustrated in Fig. 1, the initial pH of the starting aqueous solution of orthophosphoric acid was lower than those of orthophosphate salts. Thus, orthophosphoric acid had a stronger acid attack on the calcium carbonate powder. In Fig. 3(C) and (D), all intermediates were present at low contents and had almost disappeared after $48 \mathrm{~h}$ of reaction.

From the results of TG analysis, the amount of remaining calcium carbonate in the solid samples was calculated (Table 2). As expected, orthophosphoric acid led to a higher dissolution of calcium carbonate than any of the three orthophosphate salts. In all cases, after a rapid acid attack during the first hour of reaction, in which $46-73 \%$ of the calcium carbonate was dissolved, the reaction rate decreased notably. Calcium phosphate precipitates, which 

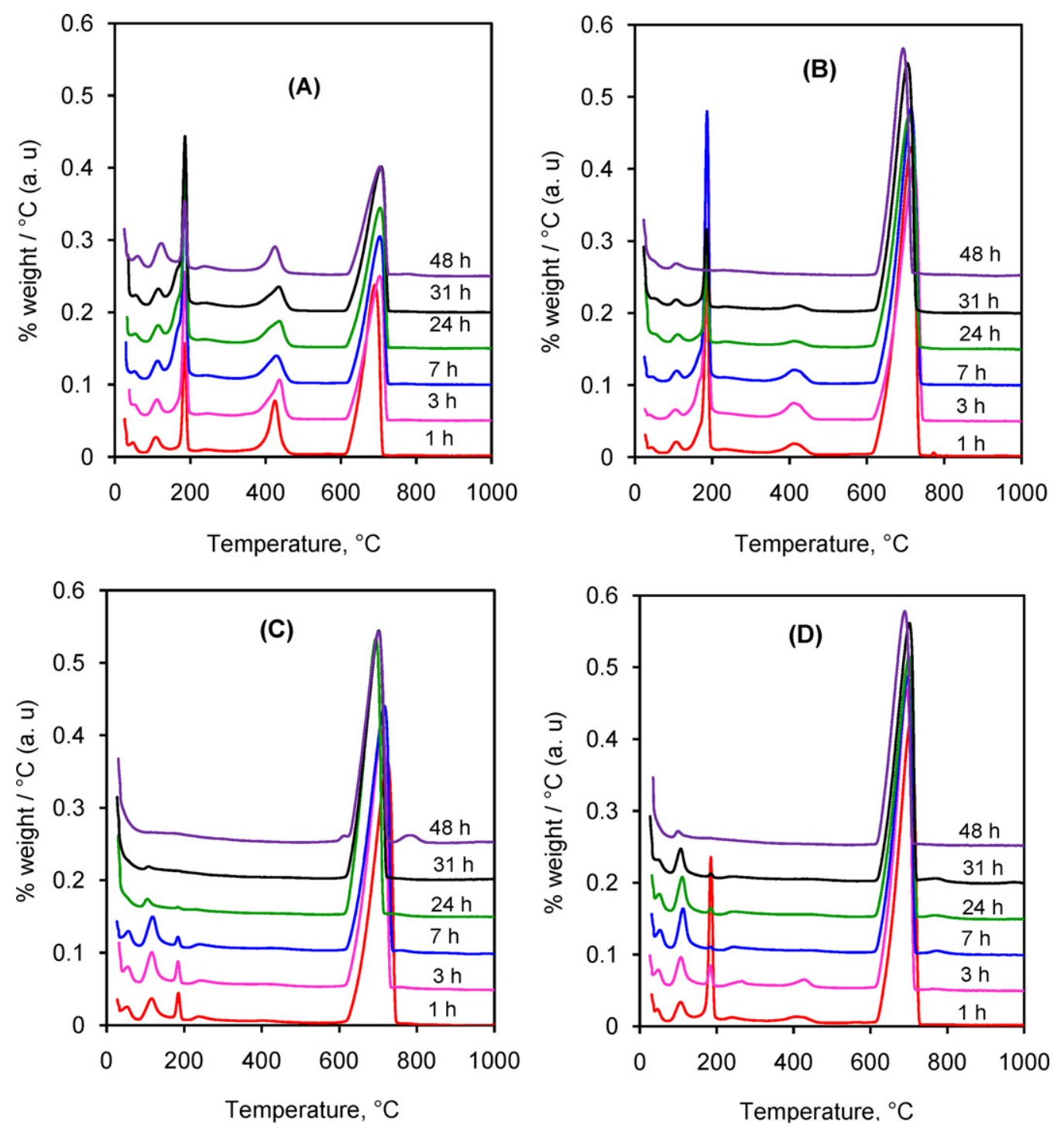

Fig. 3. DTG curves (arbitrary units) of the solid powders in the synthesis using orthophosphoric acid (A), sodium dihydrogen orthophosphate (B), potassium dihydrogen orthophosphate (C) and ammonium dihydrogen orthophosphate (D) as orthophosphate sources.

were formed during the first reaction period, might coat the surface of the calcium carbonate particles to form a biphasic structure, as observed in previous work [29]. Calcium phosphate layers of low solubility limit the contact between the calcium carbonate and soluble orthophosphate reactants, slowing the reaction rates.

All weight losses in Fig. 3 were endothermic so the corresponding DSC curves were not shown in this report.

\subsection{XRD characterization}

XRD patterns of the solid samples withdrawn at different time intervals are presented in Fig. 4. Remaining calcium carbonate showed the clearest crystalline phases in all cases. As expected, different calcium phosphate based products were identified. DCPD and DCPA were mostly present in all samples using orthophosphoric acid or sodium dihydrogen orthophosphate (Fig. 4(A) and (B)). They reached the highest contents at $24 \mathrm{~h}$ for orthophosphoric acid and at $7 \mathrm{~h}$ for sodium dihydrogen orthophosphate. Then their amount decreased, confirming their transformation into other products. On the other hand, DCPD and DCPA appeared only at the beginning of the reactions with potassium and ammonium dihydrogen orthophosphates, which is coherent with the results of TG analysis. In no cases could MCPM be detected which was in accord with its very low quantity in these solid products.

In addition to the intermediates identified by TG analysis, XRD results allowed the identification of low crystallinity Ca-HA and other apatitic compounds such as octacalcium bis(hydrogenphosphate) tetrakis(phosphate) pentahydrate (OCP, $\left.\mathrm{Ca}_{8}\left(\mathrm{HPO}_{4}\right)_{2}\left(\mathrm{PO}_{4}\right)_{4} \cdot 5 \mathrm{H}_{2} \mathrm{O}\right)$ and B-type calcium carbonate-apatite (CAP). OCP could be formed because calcium carbonate was not totally consumed after $48 \mathrm{~h}$ of reaction, leading to a deficiency of available soluble calcium to construct the complete stoichiometric hydroxyapatite structure. The hydrolysis of the DCPD, which was the main intermediate in these syntheses, could also lead to the formation of OCP [30]. For the formation of CAP, the evolved carbonic gas saturated the solution with the increase in $\mathrm{pH}$ and participated in forming carbonate-apatite by the substitution of $\mathrm{PO}_{4}{ }^{3-}$ groups by $\mathrm{CO}_{3}{ }^{2-}$ groups (B-type substitution) [31-33]. This was confirmed by IR analysis of the solid products obtained after $48 \mathrm{~h}$ of reaction (Section 3.5).

The low crystallinity of the solid products, as shown by weak broad peaks of apatitic structure, was due to the low reaction temperature of synthesis, ca. $25^{\circ} \mathrm{C}$. Higher temperatures are required for the formation of well-crystallized Ca-HA [14,34,35]. As regards 

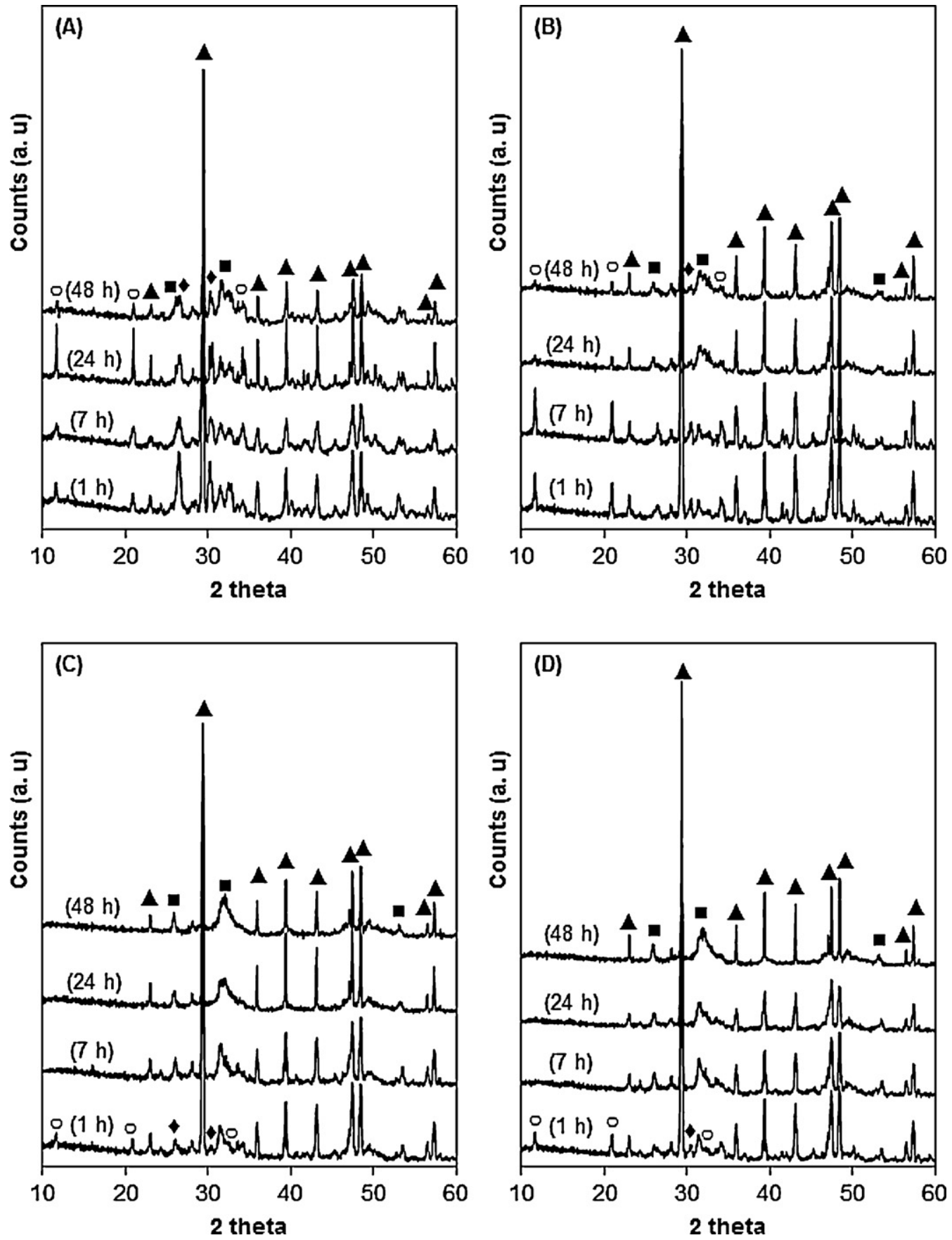

Fig. 4. XRD patterns of the solid powders in the syntheses using orthophosphoric acid (A), sodium dihydrogen orthophosphate (B), potassium dihydrogen orthophosphate (C) and ammonium dihydrogen orthophosphate (D) as orthophosphate sources. Principal diffractions of calcium carbonate (A); DCPD (o); DCPA ( $\downarrow)$; apatite structure ( $\square$ ).

the largest dissolution of calcium carbonate by orthophosphoric acid, the resulting solid product after $48 \mathrm{~h}$ of reaction was calcined at $900^{\circ} \mathrm{C}$ for $1 \mathrm{~h}$ under air atmosphere. Its XRD pattern is presented in Fig. 5.

In Fig. 5, all peaks could be attributed to the diffractions of beta-tricalcium phosphate ( $\beta$-TCP) and Ca-HA, which were both well-crystallized. Some active lime $(\mathrm{CaO})$ also appeared in small amounts. In fact, the solid product from the reaction of calcium carbonate and orthophosphoric acid contained exactly the Ca/P molar ratio of 1.67 (Table 1). However, some of initial calcium carbonate was not dissolved as verified above by TG results. This remaining calcium carbonate decomposed under thermal treatment and resulted in the formation of active lime. Most of this active lime reacted with the intermediates such as MCPM, DCPD, DCPA to form
TCP which is considered as the precursor of Ca-HA. The effect of temperature on the crystallinity of calcium phosphate based products and the formation of TCP was already observed [36-38].

\subsection{IR study}

Fig. 6 presents IR spectra of the solid products obtained after $48 \mathrm{~h}$ of reaction. In the wavelength range of $4000-1700 \mathrm{~cm}^{-1}$, only a weak broad peak at about $3600-3000 \mathrm{~cm}^{-1}$, which was attributed to water or $\mathrm{OH}^{-}$groups in apatitic channel, was observed (results not shown).

In the wavelength region of $1700-500 \mathrm{~cm}^{-1}$, residual calcium carbonate was characterized by its main peaks at $711 \mathrm{~cm}^{-1}$ and $872 \mathrm{~cm}^{-1}$. Two peaks at $1450 \mathrm{~cm}^{-1}$ and $1415 \mathrm{~cm}^{-1}$ were attributed 


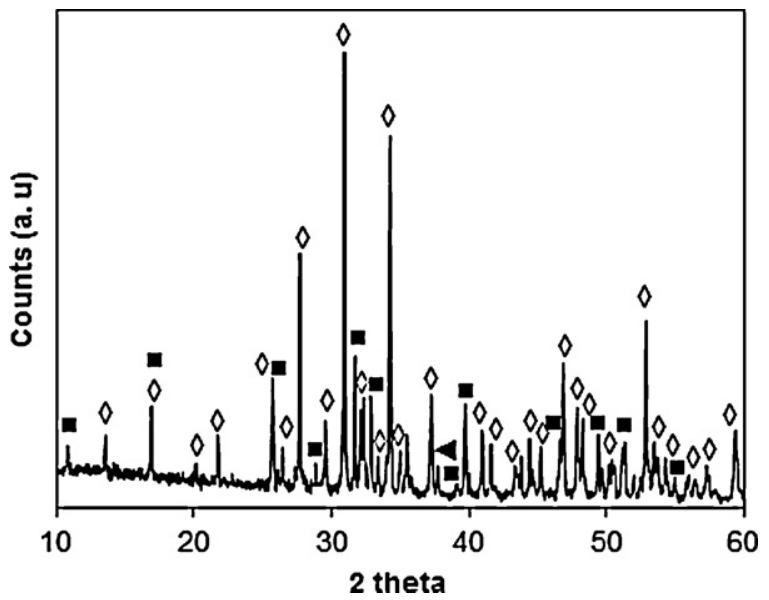

Fig. 5. XRD patterns of the calcined solid powders after $48 \mathrm{~h}$ of synthesis using orthophosphoric acid. Diffraction of TCP $(\diamond)$; Ca-HA $(\mathbf{\square})$; $\mathrm{CaO}(\triangleleft)$.

to the presence of B-type carbonate-apatite [39] which confirmed again XRD results. The intensity of these peaks decreased in the following order: $\mathrm{KH}_{2} \mathrm{PO}_{4}>\mathrm{NH}_{4} \mathrm{H}_{2} \mathrm{PO}_{4}>\mathrm{NaH}_{2} \mathrm{PO}_{4}>\mathrm{H}_{3} \mathrm{PO}_{4}$. This was in accord with the observation of $\mathrm{pH}$ evolution. The highest $\mathrm{pH}$ after $48 \mathrm{~h}$ of reaction was obtained with $\mathrm{KH}_{2} \mathrm{PO}_{4}$ which was the most favorable for the formation of carbonate anion in solution and therefore for the formation of B-type carbonate-apatite. Peaks in the wavelength ranges of $650-500 \mathrm{~cm}^{-1}$ and $1200-900 \mathrm{~cm}^{-1}$ could be attributed to different calcium phosphates present in these solid products $[39,40]$.

\subsection{Specific surface area measurement}

From the point of view of the potential applications of Ca-HA based materials for the environmental or catalysis fields, specific surface area is an important parameter to consider. Table 3 summarizes the results obtained.

In all cases, $S_{\mathrm{BET}}$ increased with the reaction time, indicating the evolution of the reaction at ambient conditions, which correlated with the change of calcium carbonate content in Table 2. The initial calcium carbonate used in this investigation had a very low $S_{\mathrm{BET}}$ $\left(<2 \mathrm{~m}^{2} / \mathrm{g}^{-1}\right)$. Despite the lower elimination level of calcium carbonate, all three orthophosphate salts led to higher $S_{\mathrm{BET}}$ in comparison to orthophosphoric acid. The solid product from the synthesis using

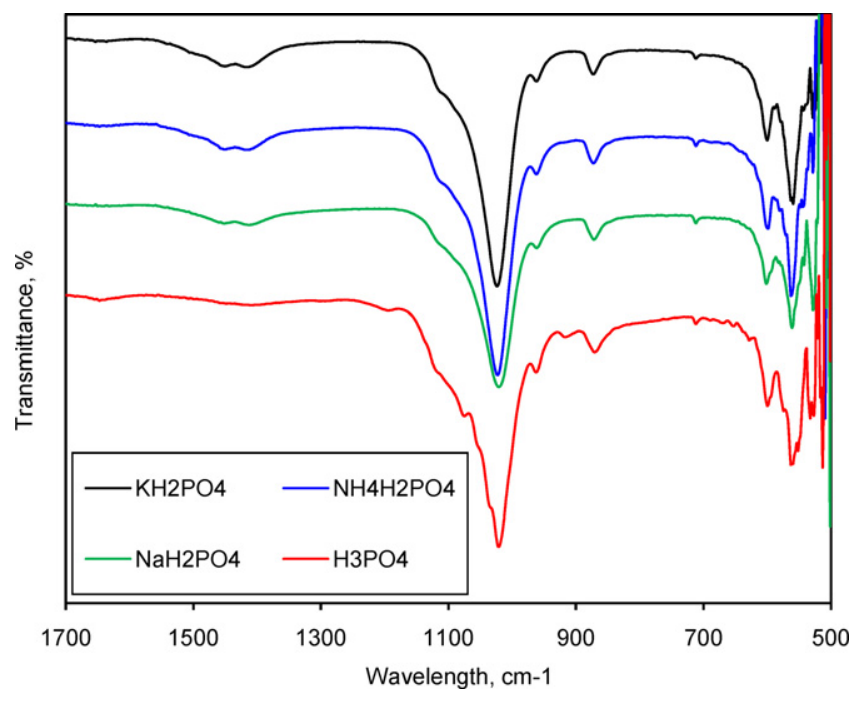

Fig. 6. IR spectra of the solid products obtained after $48 \mathrm{~h}$ of reaction.
Table 3

Specific surface area measured by BET method of the solid products after washing and drying.

\begin{tabular}{clccl}
\hline Reaction time $(\mathrm{h})$ & \multicolumn{4}{l}{ Specific surface $\left(\mathrm{S}_{\mathrm{BET}}\right)\left(\mathrm{m}^{2} / \mathrm{g}\right)$} \\
\cline { 2 - 5 } & $\mathrm{H}_{3} \mathrm{PO}_{4}$ & $\mathrm{NaH}_{2} \mathrm{PO}_{4}$ & $\mathrm{KH}_{2} \mathrm{PO}_{4}$ & $\mathrm{NH}_{4} \mathrm{H}_{2} \mathrm{PO}_{4}$ \\
\hline 3 & 12 & 5 & 17 & 13 \\
24 & 14 & 23 & 68 & 21 \\
48 & 27 & 44 & 105 & 75 \\
\hline
\end{tabular}

potassium dihydrogen orthophosphate showed the highest $S_{\mathrm{BET}}$ of $105 \mathrm{~m}^{2} / \mathrm{g}$ after $48 \mathrm{~h}$ of reaction.

\subsection{SEM-EDX analysis}

The solid products obtained after $48 \mathrm{~h}$ of reaction were examined by SEM-EDX and some examples are presented in Fig. 7. On the left-hand side ( $200 \mu \mathrm{m}$ scale), different groups of particles were present with a high occurrence of small particles. On the right-hand side ( $2 \mu \mathrm{m}$ scale), the surfaces of big particles are presented with the same enlargement. Particles of the solid products formed from orthophosphoric acid (A2) and sodium dihydrogen orthophosphate (B2) had a compact appearance with some sheet structure that could be due to the presence of DCPD in these solids [41]. On the other hand, particles formed from potassium dihydrogen orthophosphate (C2) and ammonium dihydrogen orthophosphate (D2) appeared much more porous and the primary platelets forming the aggregates could be clearly observed.

EDX analysis was also performed and in all cases, we observed the presence of $\mathrm{Ca}, \mathrm{P}, \mathrm{O}$ and $\mathrm{C}$ corresponding to calcium phosphate based products. The presence of carbon was partly due to the carbonic gas in air and CAP, but could also be due to the remaining calcium carbonate. On the other hand, no traces of potassium, sodium or nitrogen were detected. Thus, there was no incorporation of these elements into the first surface layers of calcium phosphates and simple washing prevented the possible inclusion of these elements on the surface of the solid products.

\subsection{Particle size distribution and adsorption-desorption isotherm measurements}

To confirm the results of $S_{\mathrm{BET}}$ and SEM analysis, particle size distribution and isothermal adsorption-desorption measurements were investigated. Fig. 8 shows the particle size distribution of the initial calcium carbonate powder which could be considered as a Gaussian-like type for both volume and number distributions.

Fig. 9 shows the comparison of number (left) or volume (right) distributions for the solid products obtained at different reaction times. The number distributions revealed that most particles were present in the range from 0.4 to $1 \mu \mathrm{m}$ with more than $97 \%$ of the cumulative total. At each reaction time ( $3 \mathrm{~h}$ or $24 \mathrm{~h}$ or $48 \mathrm{~h}$ ), there was very little difference between the four orthophosphate sources used. On the other hand, the volume distributions showed that more than $98 \%$ of accumulative volume belonged to the larger particles category $(>1 \mu \mathrm{m})$.

For the family of particles smaller than $1 \mu \mathrm{m}$, the median diameter $\left(d_{50}\right)$ increased slightly with the reaction time indicating their slow growth in the present reaction conditions. For the larger particles family $(>1 \mu \mathrm{m})$, in most cases, we observed the formation of three groups as follows: $1-10 \mu \mathrm{m}, 10-80 \mu \mathrm{m}$ and $80-350 \mu \mathrm{m}$. The common tendency of these groups was the increase in volume of the $80-350 \mu \mathrm{m}$ group and the decrease in volume of the $1-10 \mu \mathrm{m}$ and $10-80 \mu \mathrm{m}$ groups during the course of the reaction.

Generally, the specific surface area of a material is attributed to both the external surface of particles and the internal surface of 

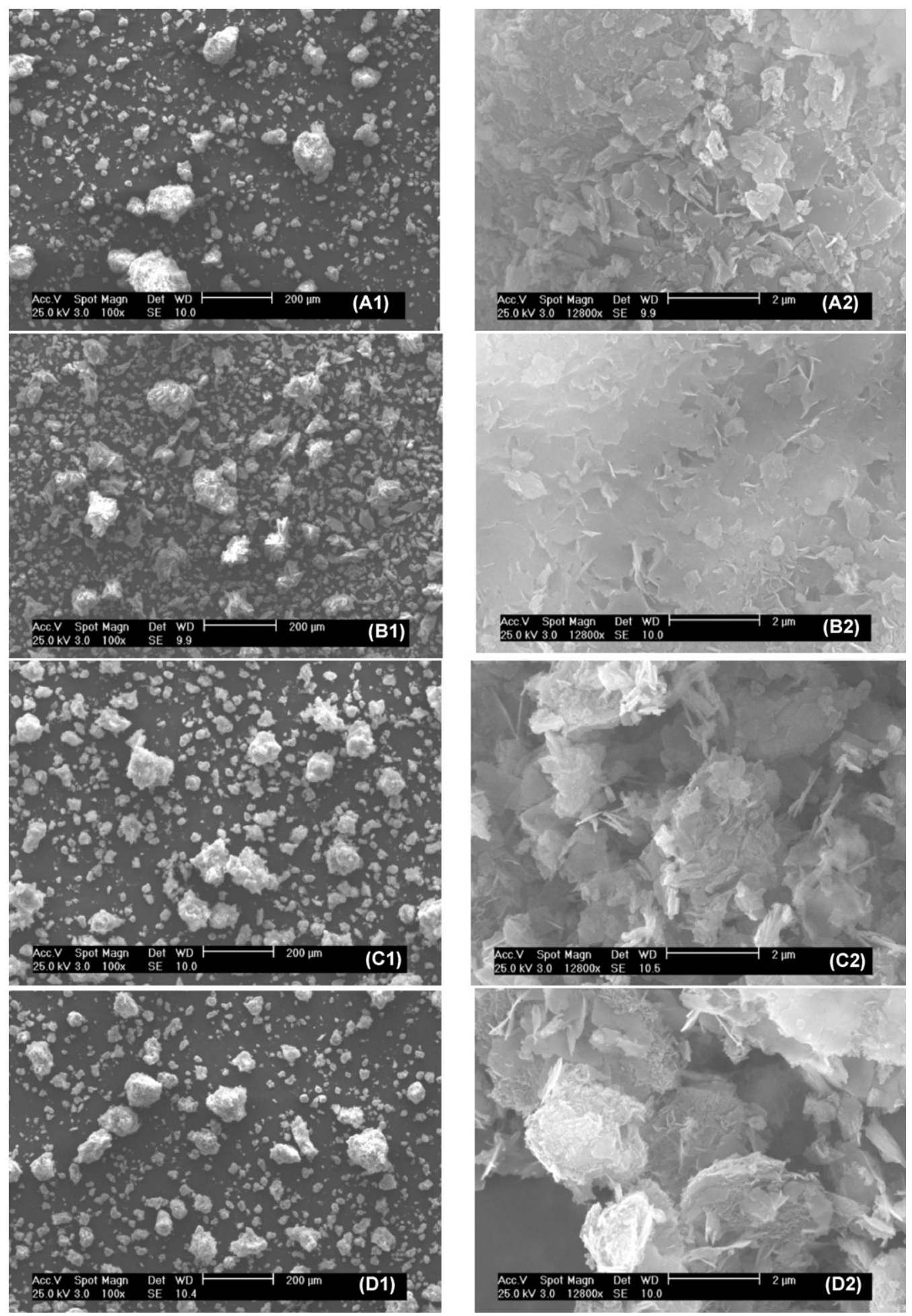

Fig. 7. SEM analysis of the solid products after $48 \mathrm{~h}$ of reaction using orthophosphoric acid (A1, A2), sodium dyhydrogen phosphate (B1, B2), potassium dihydrogen phosphate $(\mathrm{C} 1, \mathrm{C} 2)$ and ammonium dihydrogen phosphate (D1, D2).

pores if the material is porous. From the results of the particle size distribution analysis in Fig. 9, the differences in the specific surface areas $\left(S_{\mathrm{BET}}\right)$ in Table 3 must be predominantly due to the porosity of the solids. Thus adsorption-desorption isotherms were carried out for four solids obtained after $48 \mathrm{~h}$ of reaction (Fig. 10).

All isotherms could be attributed to Type II solids with a hysteresis loop of Type H3 in the IUPAC classification of physisorption isotherms [42].
Using the BJH method [43] for both adsorption and desorption branches of isotherms, the porous volume $\left(V_{\mathrm{p}}\right)$, calculated specific surface area $\left(S_{\mathrm{c}}\right)$ and pore mean diameter $\left(D_{\mathrm{p}}\right)$ could be derived. They are presented in Table 4.

For each solid product, the calculated specific surface area from the desorption branch $\left(S_{C}^{\text {des }}\right)$ was higher than the specific surface area $\left(S_{\mathrm{BET}}\right)$. This result was characteristic of an unstable porous structure for aggregates as well as for the sheet structure of solids, 


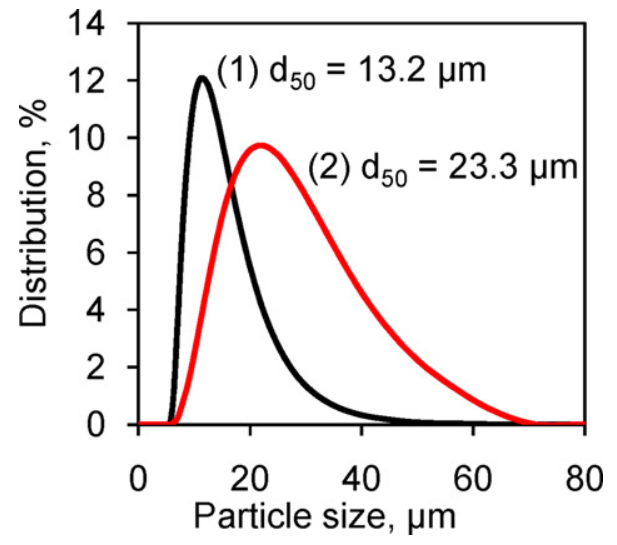

Fig. 8. Particle size analysis of the initial calcium carbonate powder; (1) and (2): particle number and volume distribution, respectively.
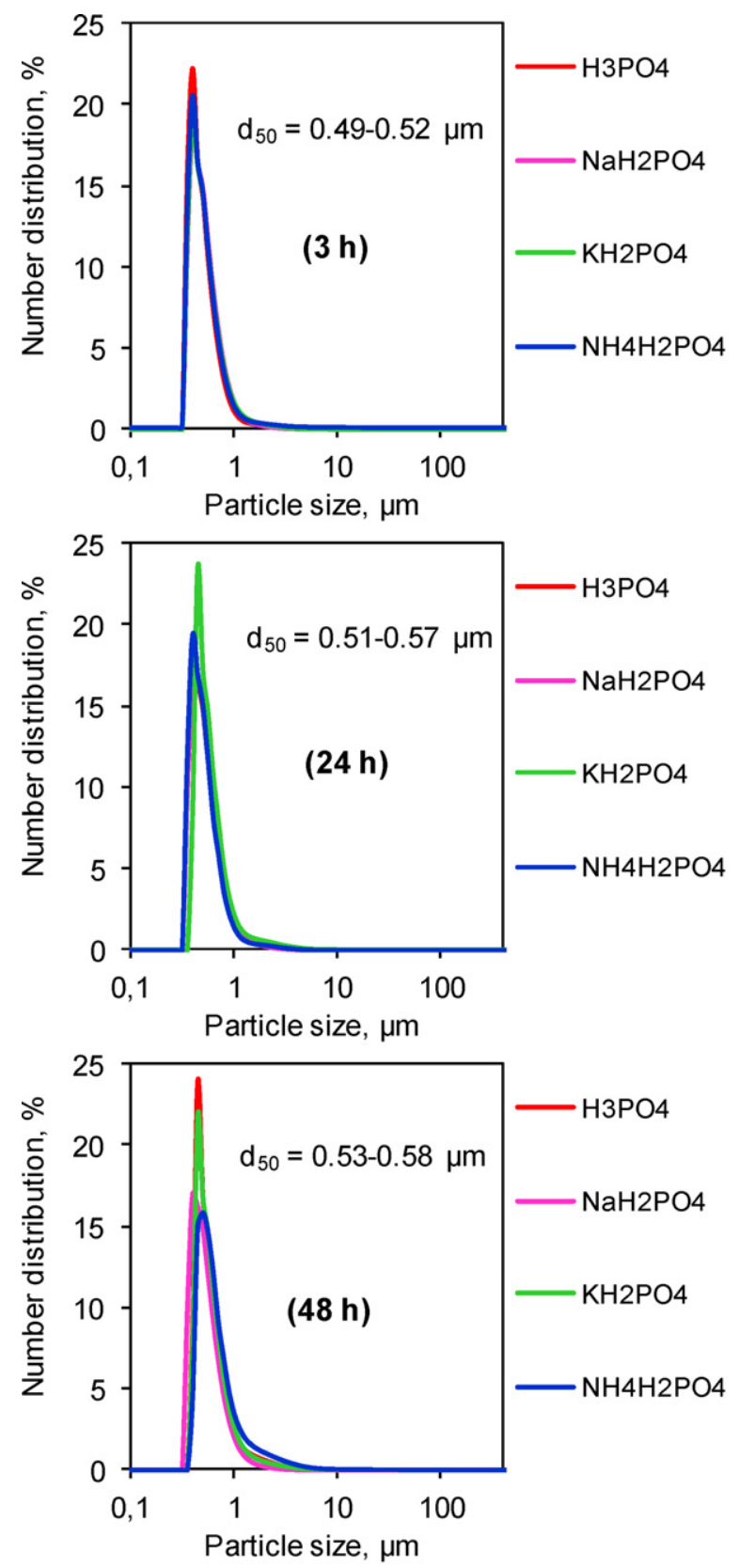

which modify their pore volumes under the effect of high relative pressure. The pore mean diameters were all in the mesoporous range.

\subsection{Reaction pathway}

The formation of a large majority (97\%) of small calcium phosphate particles $(<1 \mu \mathrm{m})$ from an initial calcium carbonate of much larger particle size confirmed the arguments in favor of dissolution of calcium carbonate to release calcium cations (Eq. (1)) and the formation of different calcium phosphate precipitates from these dissolved calcium cations and orthophosphate species (Eq. (2)). A reaction pathway could be proposed for the evolution of the reaction as given in Scheme 1.

First, calcium carbonate powder was dissolved in acid solution to form soluble calcium cations. These cations were then
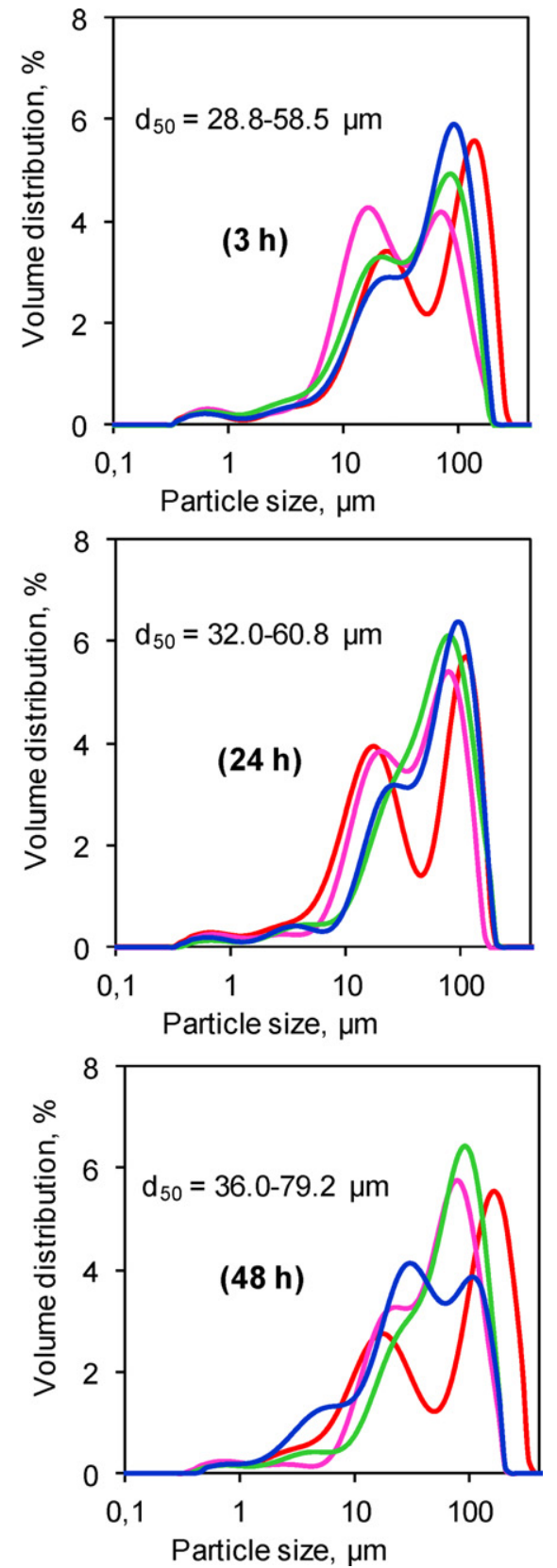

Fig. 9. Number (left) and volume (right) distribution as a function of particle size of the solid products at different reaction times and pure $\mathrm{CaCO}_{3}$; particle size is in base 10 logarithmic scale. 

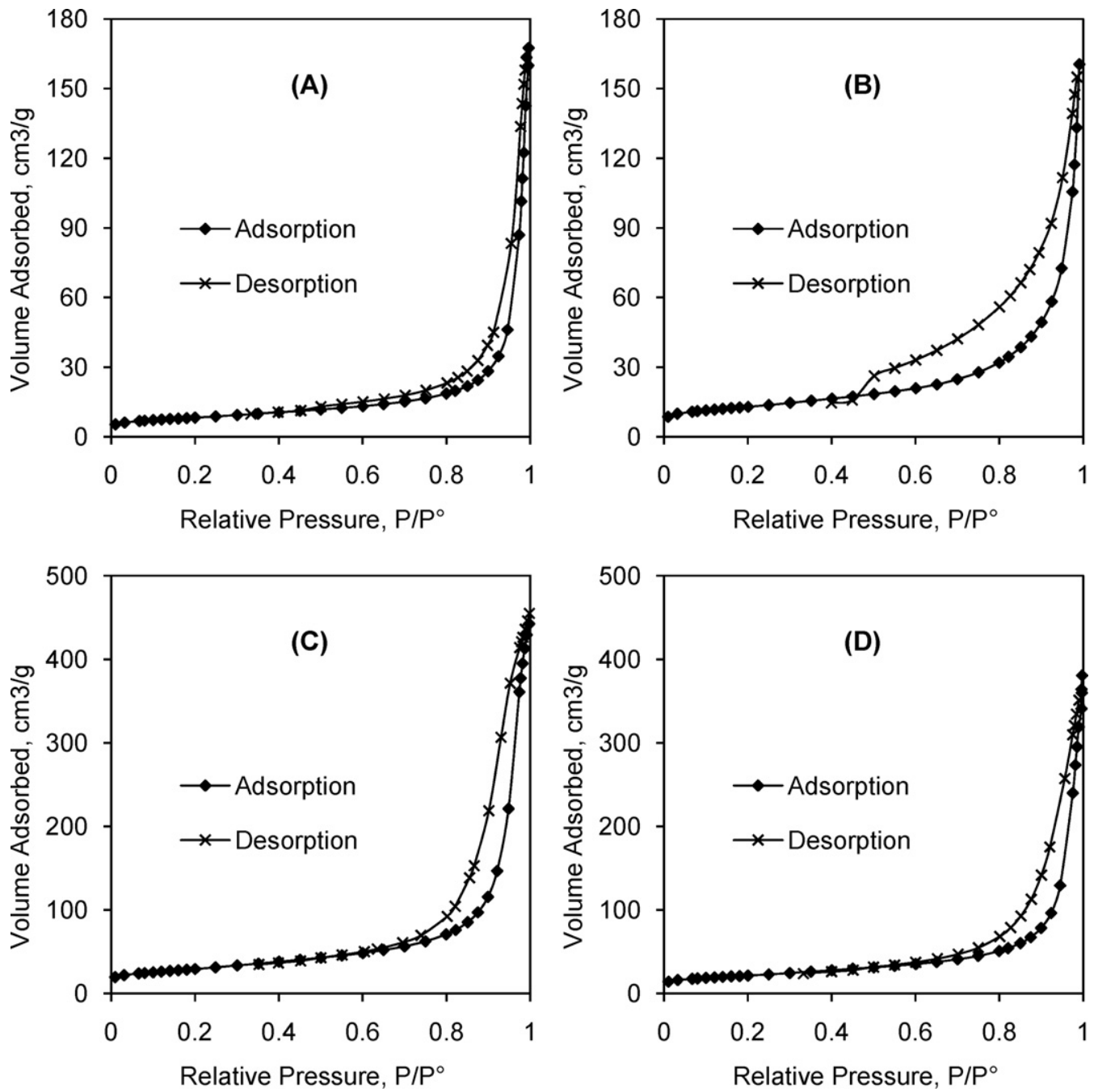

Fig. 10. Isotherm plots of the solid products obtained at $48 \mathrm{~h}$ of reaction from (A) orthophosphoric acid; (B) sodium dihydrogen orthophosphate; (C) potassium dihydrogen orthophosphate and (D) ammonium dihydrogen orthophosphate.

precipitated with orthophosphate anions to form MCPM and DCPD as the first intermediates. MCPM evolved to DCPD by the reaction with more calcium cations. DCPD was then transformed into DCPA as another intermediate. These intermediates had the $\mathrm{Ca} / \mathrm{P}$ molar ratio of $0.5 / 1$ or $1 / 1$. With the on-going reaction, calcium carbonate continued to be dissolved, accompanying the increase in $\mathrm{pH}$ by the consumption of protons. Under these conditions, DCPD and DCPA developed an apatitic composition. This transformation was slow and depended on the orthophosphate source. The presence of carbonic gas or (bi)carbonate anions in the reaction mixture led to the formation of CAP in parallel with the formation of Ca-HA as the final product. Throughout the reaction, the agglomeration phenomenon of primary particles led to the formation of agglomerates with sizes up to $350 \mu \mathrm{m}$. The final solid product after $48 \mathrm{~h}$ of reaction contained principally a mixture of Ca-HA, CAP and some left over $\mathrm{CaCO}_{3}$. Other intermediates including MCPM, DCPD and DCPA could also be present, depending on the initial orthophosphate source. Finally, the calcination at $900^{\circ} \mathrm{C}$ for $1 \mathrm{~h}$ of the solid

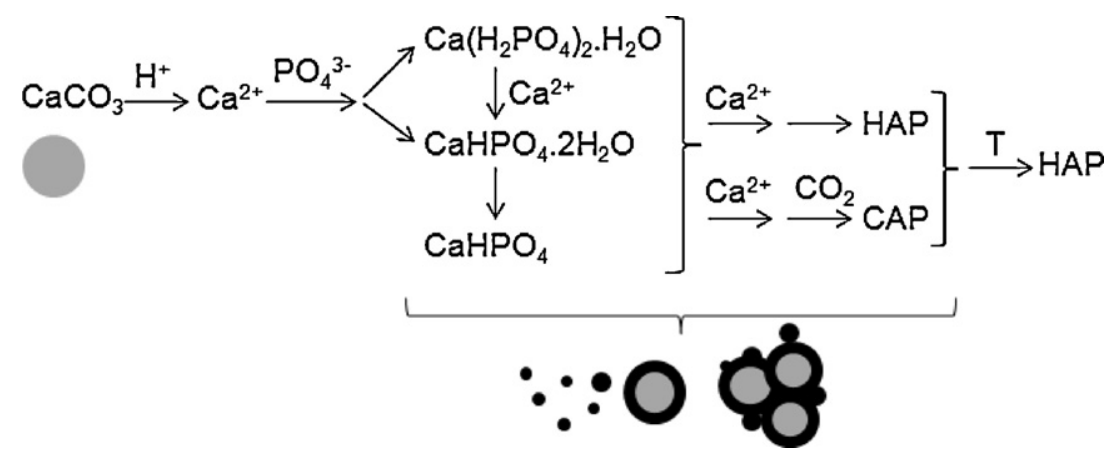

Scheme 1. Reaction pathway in the Ca-HA synthesis. 
Table 4

Results calculated from the isotherms of the solid products at $48 \mathrm{~h}$ of reaction: (A) orthophosphoric acid; (B) sodium dihydrogen orthophosphate; (C) potassium dihydrogen orthophosphate and (D) ammonium dihydrogen orthophosphate.

\begin{tabular}{|c|c|c|c|c|c|c|c|}
\hline \multirow[t]{2}{*}{ Product } & \multirow[t]{2}{*}{$S_{\mathrm{BET}}\left(\mathrm{m}^{2} / \mathrm{g}\right)$} & \multicolumn{3}{|c|}{ Results from the adsorption } & \multicolumn{3}{|c|}{ Results from the desorption } \\
\hline & & $V_{\mathrm{p}}^{\text {ads }}\left(\mathrm{cm}^{3} / \mathrm{g}\right)$ & $S_{\mathrm{c}}^{\text {ads }}\left(\mathrm{m}^{2} / \mathrm{g}\right)$ & $D_{\mathrm{p}}^{\mathrm{ads}}(\mathrm{nm})$ & $V_{\mathrm{p}}^{\text {des }}\left(\mathrm{cm}^{3} / \mathrm{g}\right)$ & $S_{c}^{\text {des }}\left(\mathrm{m}^{2} / \mathrm{g}\right)$ & $D_{\mathrm{p}}^{\text {des }}(\mathrm{nm})$ \\
\hline (A) & 27 & 0.25 & 25 & 39 & 0.26 & 32 & 32 \\
\hline (B) & 44 & 0.24 & 39 & 25 & 0.25 & 83 & 12 \\
\hline (C) & 105 & 0.68 & 98 & 28 & 0.65 & 136 & 19 \\
\hline (D) & 75 & 0.52 & 69 & 30 & 0.49 & 94 & 20 \\
\hline
\end{tabular}

product issue from the dissolution of calcium carbonate in the solution of orthophosphoric acid resulted in the formation of a biphasic mixture of well-crystalline TCP and Ca-HA.

\section{Conclusion}

For the first time, a comparative study on the direct synthesis of Ca-HA from calcium carbonate powder and different orthophosphates was undertaken. Orthophosphoric acid was the most interesting orthophosphate source since it was the most efficient for the dissolution of calcium carbonate and was the only reactant leading to complete consumption by precipitation of starting orthophosphate species within $48 \mathrm{~h}$.

Porous solid products were formed with all orthophosphate reactants. The porosity of the products was due to the formation of large aggregates which had an unstable porous structure. The difference in the porosity explained the difference in the specific surface area $\left(S_{\mathrm{BET}}\right)$ of the solid products. On the other hand, particle size distributions were relatively similar to each other.

Using TG and XRD characterizations, different intermediates and their evolution during the reaction could be identified. A reaction pathway could be proposed.

Future work will focus on the improvement of the dissolution of calcium carbonate using orthophosphoric acid, for example at higher reaction temperature, together with TEM observations to confirm a simple one-step production route to economical $\mathrm{Ca}-\mathrm{HA}$.

\section{Acknowledgments}

The authors gratefully acknowledge financial support from Solvay Group. Our gratitude goes to colleagues at RAPSODEE Center, Christine Rolland, Sylvie Del Confetto, Philippe Accart and Denis Marty for their technical help.

\section{References}

[1] R.Z. Legeros, S. Lin, R. Rohanizadeh, D. Mijares, J.P. Legeros, Journal of Materials Science Materials in Medicine 14 (2003) 201-209.

[2] S.V. Dorozhkin, M. Epple, Angewandte Chemie International Edition 41 (17) (2002) 3130-3146.

[3] A. Venugopal, M.S. Scurrell, Applied Catalysis A: General 245 (2003) 137-147.

[4] C. Boucetta, M. Kacimi, Applied Catalysis A: General 356 (2009) 201-210.

[5] M.I. Dominguez, F. Romero-Sarria, M.A. Centeno, J.A. Odriozola, Applied Catalysis B: Environmental 87 (2009) 245-251.

[6] H. Nishikawa, S. Kato, T. Ando, Journal of Molecular Catalysis A: Chemical 236 (2005) 145-148

[7] J.A. Gomez del Rio, P.J. Morando, D.S. Cicerone, Journal of Environment Management 71 (2004) 169-177.

[8] W. Lemlikchi, P. Sharrock, M.O. Mecherri, M. Fiallo, Waste and Biomass Valorization, in press.
[9] A. Nzihou, P. Sharrock, Waste Management 22 (2002) 235-239.

[10] I. Smiciklas, A. Onjia, S. Raicevic, Đ. Janackovic, M. Mitric, Journal of Hazardous Materials 152 (2008) 876-884.

[11] K. Lin, J. Pan, Y. Chen, R. Cheng, X. Xu, Journal of Hazardous Materials 161 (2009) 231-240.

[12] P. Koutsoukos, Z. Amjad, M.B. Tomson, G.H. Nancollas, Journal of the American Chemical Society 102 (1980) 1553-1557.

[13] K.S. TenHuisen, P.W. Brown, Biomaterials 19 (1998) 2209-2217.

[14] S. Jinawath, D. Pongkao, W. Suchanek, M. Yoshimura, International Journal of Inorganic Materials 3 (2001) 997-1001.

[15] W. Kim, F. Saito, Ultrasonics Sonochemistry 8 (2001) 85-88.

[16] D.M. Liu, T. Troczynski, W. Tseng, Journal of Biomaterials 23 (2002) 1227-1236.

[17] L.L. Ames, Economic Geology and the Bulletin of the Society of Economic Geologists 54 (1959) 829-841.

[18] K.P. Krajewski, Sedimentology 31 (1984) 443-470.

[19] N. Nassif, F. Martineau, O. Syzgantseva, F. Gobeaux, M. Willinger, T. Coradin, S. Cassaignon, T. Azais, M.M. Giraud-Guille, Chemistry of Materials 22 (2010) 3653-3663

[20] E. Hayek, H. Newesely, Inorganic Syntheses 7 (1963) 63-65.

[21] J.K. Lee, D.S. Song, K.H. Hwang, D.S. Seo, Key Engineering Materials 342-343 (2007) 661-664

[22] A. Osaka, Y. Miura, K. Takeuchi, M. Asada, K. Takahashi, Journal of Materials Science Materials in Medicine 2 (1991) 51-55.

[23] J.F. Conn, L. Jessen, United States Patent 4,324,772 (1982).

[24] L. Bernard, M. Freche, J.L. Lacout, B. Biscans, Chemical Engineering Science 55 (2000) 5683-5692.

[25] V. Stanica, S. Dimitrijevic, J. Antic-Stankovic, M. Mitric, B. Jokic, I.B. Plecas, S. Raicevic, Applied Surface Science 256 (2010) 6083-6089.

[26] M.C. Chang, Journal of Materials Science Materials in Medicine 19 (2008) 3411-3418.

[27] J.C. Elliott, Studies in Inorganic Chemistry 18: Structure and Chemistry of the Apatites and Other Calcium Orthophosphates, Elsevier, Amsterdam/London/New York/Tokyo, 1994, pp. 9-29.

[28] D.W. Kim, I.S. Cho, J.Y. Kim, H.L. Jang, G.S. Han, H.S. Ryu, H. Shin, H.S. Jung, H. Kim, K.S. Hong, Langmuir 26 (1) (2010) 384-388.

[29] C. Verwilghen, M. Chkir, S. Rio, A. Nzihou, P. Sharrock, G. Depelsenaire, Materials Science and Engineering C 29 (2009) 771-773.

[30] W.E. Brown, J.R. Lehr, J.P. Smith, A.W. Frazier, Journal of the American Chemical Society 79 (19) (1957) 5318-5319.

[31] F. Yao, J.P. LeGeros, R.Z. LeGeros, Acta Biomaterialia 5 (2009) 2169-2177.

[32] T.I. Ivanova, O.V. Frank-Kamenetskaya, A.B. Koltsov, V.L. Ugolkov, Journal of Solid State Chemistry 160 (2011) 340-349.

[33] F. Bel Hadj Yahia, M. Jemal, Thermochimica Acta 505 (2010) 22-32.

[34] M. Yoshimura, P. Sujaridworakun, F. Koh, T. Fujiwara, D. Pongkao, A. Ahniyaz, Materials Science and Engineering C 24 (2004) 521-525.

[35] S. Jinawath, D. Polchai, M. Yoshimura, Materials Science and Engineering C 22 (2002) 35-39.

[36] C. Verwilghen, Thèse de doctorat, Université de Toulouse III, France, 2006, p. 103.

[37] R.Z. LeGeros, Chemical Reviews 108 (2008) 4742-4753.

[38] S. Nadir, A. Belainass, A. Irhzo, J.L. Lacout, Phosphorus, Sulfur, and Silicon and the Related Elements $112(1-4)(1996) 33-40$.

[39] M.E. Fleeta, X. Liu, Biomaterials 26 (2005) 7548-7554.

[40] Y. Guo, Y. Zhou, D. Jia, H. Tang, Microporous and Mesoporous Materials 118 (2009) 480-488.

[41] G. Cama, F. Barberis, M. Capurro, L. Di Silvio, S. Deb, Materials Chemistry and Physics 130 (2011) 1139-1145.

[42] K.S.W. Sing, D.H. Everett, R.A.W. Haul, L. Moscou, R.A. Pierotti, J. Rouquerol, T. Siemieniewska, Pure and Applied Chemistry 57 (4) (1985) 603-619.

[43] E.P. Barrett, L.G. Joyner, P.P. Halenda, Journal of the American Chemical Society 73 (1) (1951) 373-380. 